\title{
Effect of Aging and Respiratory Infection to Duration of Hospitalization in Asthma Exacerbationy
}

Hirochiyo Sawaguchi* and Masato Muraki

Department of Respiratory Medicine and Allergy, Nara Hospital, Kinki University Faculty of Medicine, Ikoma, Japan

\begin{abstract}
Objective: We investigated the factors that delay recovery from asthma exacerbation. Analyses were performed on subjects who needed to be admitted due to asthma exacerbation in our hospital from 2008 to 2014 .

Method: Ninety-five adult subjects who needed hospitalization with asthma exacerbation were analyzed. The number of patients and the duration of hospital stay were analyzed statistically according to age (under 65 years of age versus 65 years or over), sex and respiratory infection.

Results: The numbers of males and females were 34 and 61, respectively. The average duration of hospitalization in patients 65 years or over was $14.0 \pm 8.7$ days, and that in those under 65 years of age was $8.9 \pm 4.2$ days $(\mathrm{P}=0.0006)$. Twenty-nine patients had respiratory infection while 16 did not in those under 65 years of age. The durations of hospital stay in patients under 65 years of age with and without respiratory infection were $8.1 \pm 3.8$ and $10.8 \pm 4.3$ days, respectively $(P=0.04)$. Thirty-three patients had respiratory infection and 17 patients did not in those aged 65 years or over. The durations of hospital stay in patients 65 years or over with and without respiratory infection were $15.0 \pm 9.3$ and $12.4 \pm 8.1$ days, respectively $(P=0.34)$.

Conclusion: Being elderly (65 years or over) is a factor that prolongs the duration of hospital stay for asthma exacerbation. Respiratory infection seems to be a major factor which influence the duration of hospitalization for asthma exacerbation in patients under 65 years of age. On the other hand, respiratory infection is not a major factor of the duration of hospitalization for asthma exacerbation in patients 65 years over or over.
\end{abstract}

Keywords: Bronchial asthma; Hospital admission with asthma attack

\section{Introduction}

Viral or bacterial infections are very important in inpatients with asthma exacerbation $[1,2]$. On the other hand, the difficulty of treatment for elderly patients with asthma is known [3-6]. However, there have been few studies investigating the factors that delay recovery from asthma exacerbation. Therefore, we evaluated the effects of age and respiratory infection on the duration of hospitalization for asthma exacerbation in patients from 2008 to 2014 .

\section{Methods}

\section{Study subjects and laboratory analysis}

The subjects comprised all 95 patients with asthma who needed hospitalization due to asthma exacerbation and who was admitted to the Department of Respiratory Medicine and Allergology at Nara Hospital, Kinki University Faculty of Medicine, from January 2008 to December 2014. The patients consisted of 35 males and 61 females aged 19 to 90 years. The diagnosis of asthma, its exacerbation and the presence of respiratory infection were comprehensively judged by chest physicians and/or allergists based on symptoms, physical examinations, spirometry, chest roentgenogram and blood, urine, throat swab or sputum examination. The asthma of all patients was fundamentally managed under the Global Initiative for Asthma (GINA) guidelines $[7,8]$ at that time and infectious diseases were adequately controlled based on a variety of examinations. The age was divided into elderly (65 years or over) and nonelderly (under 65 years). The relationships between age, sex or respiratory infection and duration of hospitalization were investigated. This retrospective study was approved by the Institutional Review Board at Nara Hospital, Kinki University Faculty of Medicine, and was conducted in accordance with the principles expressed in the
Declaration of Helsinki. None of the authors have received any fund for this study.

\section{Statistical analysis}

Data are summarized as the mean \pm standard deviation (SD). The duration of hospitalization can be considered to have a normal distribution. Therefore the significance of differences was assessed using paired t-test and a difference of $\mathrm{P}<0.05$ was considered statistically significant $[9,10]$.

\section{Results}

The clinical characteristics of the patients are presented in Table 1. The severity of asthma exacerbation was classified according to GINA guidelines $[7,8]$. The distribution of patient numbers according to age by sex is presented in Figure 1. Male patients numbered 34 and females 61 . There were no deaths during the study period and all patients left the hospital. The duration of hospitalization of the patients 65 years or over versus those under 65 years is shown in Figure 2. The average duration of hospitalization of patients 65 years or over was $14.0 \pm$

${ }^{*}$ Corresponding author: Hirochiyo Sawaguchi, MD, PhD, Department of Respiratory Medicine and Allergy, Nara Hospital, Kinki University Faculty of Medicine, Ikoma, Japan, Tel: 0743-77-0880; E-mail: sawaguch@nara.med.kindai.ac.jp

Received November 26, 2015; Accepted December 29, 2015; Published December 31, 2015

Citation: Sawaguchi H, Muraki M (2015) Effect of Aging and Respiratory Infection to Duration of Hospitalization in Asthma Exacerbation. J Clin Respir Dis Care 1: 105. doi: 10.4172/ JCRDC. 1000105

Copyright: (c) 2015 Sawaguchi $\mathrm{H}$, et al. This is an open-access article distributed under the terms of the Creative Commons Attribution License, which permits unrestricted use, distribution, and reproduction in any medium, provided the original author and source are credited. 


\begin{tabular}{|c|c|}
\hline Clinical Characteristic & Number of Subjects \\
\hline Age range; Mean(years) & $(19-90) ; 60.2$ \\
\hline Sex, Male: Female & $34: 61$ \\
\hline Medication Before Hospitalization \\
\hline ICS only or ICS with other antiasthmatics \\
\hline SABA only & 59 \\
\hline LABA only & 3 \\
\hline Theophylline only & 3 \\
\hline Leukotriene receptor antagonist only & 1 \\
\hline Combination of Anti asthmatics excluding ICS & 3 \\
\hline No medication(include self-interruption) & 21 (male 5, female 16) \\
\hline Severity of Asthma exacerbation at hospitalization \\
\hline Continuation of moderate attack & 87 \\
\hline Severe/imminent attack & 8 \\
\hline
\end{tabular}

Table 1: Clinical characteristics of the subjects.

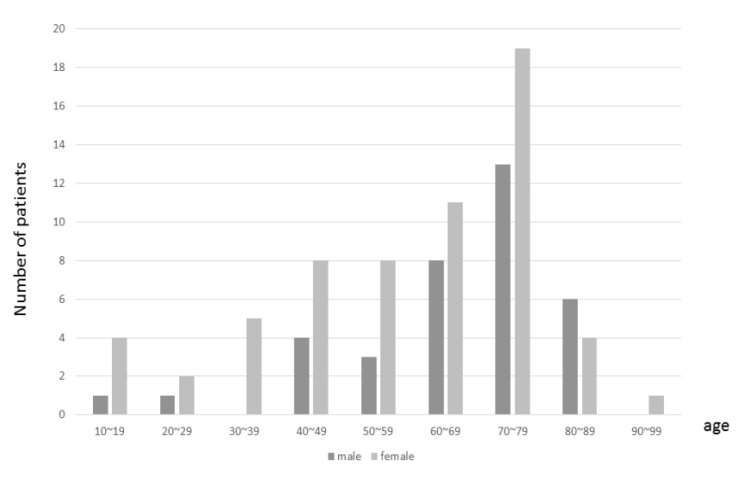

Fig. 1

Figure 1: Number of adult patients that required hospitalization due to asthma exacerbation according to age by sex from 2008 to 2104 is presented.
8.7 days and that of those under 65 years was $8.9 \pm 4.2$ days. There was a statistically significant difference between the two age groups $(\mathrm{P}=0.0006)$. The types of respiratory infection with asthma exacerbation are shown in Table 2. The duration of hospitalization in the patients under 65 years of age is shown in Figure 3 by classifying patients with and without the complication of respiratory infection. Twenty-nine patients were complicated with respiratory infection and 16 patients were not complicated with respiratory infection. The average duration of hospitalization was $8.1 \pm 3.8$ days in the patients under 65 years of age with respiratory infection. On the other hand, the average duration of hospitalization was $10.8 \pm 4.3$ days in the patients under 65 years of age without respiratory infection. There was a statistically significant difference between these two groups $(\mathrm{P}=0.04)$.

In the patients 65 years or over, 33 patients were complicated with respiratory infection and 17 patients were not. The duration of hospitalization in the patients 65 years or over is shown in Figure 4 by classifying patients with and without the complication of respiratory. The average duration of hospitalization in the patients 65 years or over was $15.0 \pm 9.3$ days in patients with respiratory infection. And the average duration of hospitalization was $12.4 \pm 8.1$ days in patients without respiratory infection. There was no statistically significant difference between these two groups $(\mathrm{P}=0.34)$.

\section{Discussion}

In the present study, the duration of hospitalization as a substitute for delayed recovery from asthma exacerbation was investigated. In

\begin{tabular}{|l|c|c|}
\hline Contents & Nonelderly (<65 years) & Elderly ( $\mathbf{~ 6 5}$ years) \\
\hline Common Cold & 10 & 8 \\
\hline Influenza & 3 & 1 \\
\hline Bronchitis & 13 & 18 \\
\hline Pneumonia & $\begin{array}{c}\text { Streptococcus Pneumonia } \\
\text { Moraxella catarrhalis 1 } \\
\text { Others 10 }\end{array}$ & $\begin{array}{c}\text { Streptococcus Pneumonia 4 } \\
\text { Moraxella catarrhalis 1 } \\
\text { Others 13 }\end{array}$ \\
\hline Tonsillitis & 1 & 6 \\
\hline Bronchitis with Rhinitis & 1 & \\
\hline
\end{tabular}

Table 2: Contents of respiratory infection.

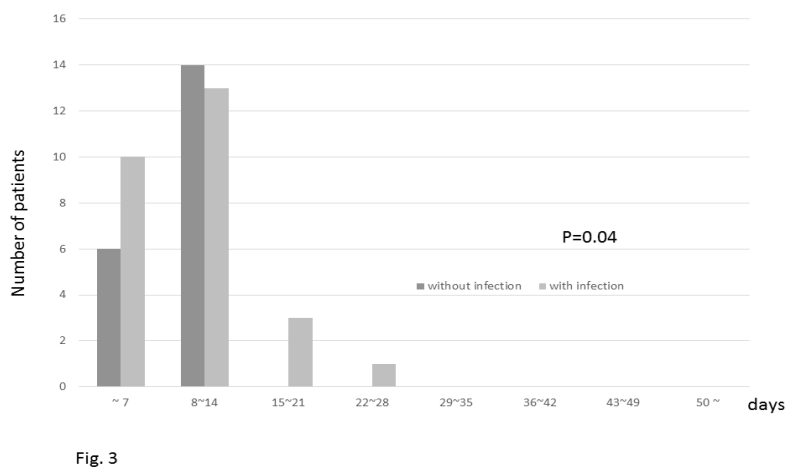

Figure 3: Duration of hospital stays between patients with respiratory infection and patients without respiratory infection in nonelderly (19-64 years old) is shown. There is a statistically significant difference in the average duration of hospitalization between the presence and absence of complication of respiratory infection $(P=0.04)$. 


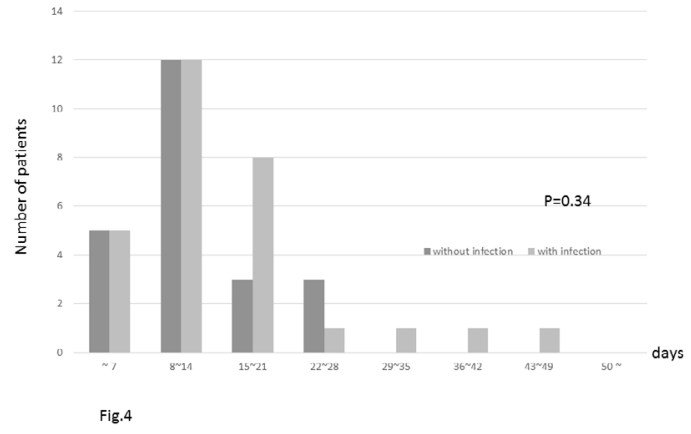

Figure 4: Duration of hospital stays between patients with respiratory infection and patients without respiratory infection in elderly (65-90 years old) is presented. There is no significant difference in the average duration of hospitalization between the presence and absence of complication of respiratory infection $(\mathrm{P}=0.34)$.

addition, the causative factors were also explored. The proportions of the elderly were similar for the male and female patients. The duration of hospitalization in elderly patients was longer than that in nonelderly ones. This suggests that asthma exacerbation in elderly patients is more difficult to cure than in younger ones. Irrespective of age, respiratory infection was an accompanying complication in more than $60 \%$ of cases. In nonelderly subjects, the duration of hospitalization in patients with respiratory infection was significantly longer than that in patients without

Respiratory infection. Influenza virus not only induces asthma exacerbation [11], but also increases asthma mortality [12]. A variety of respiratory viruses in addition to influenza virus also induce asthma exacerbation [11,13]. Bacterial organisms such as Streptococcus pneumonia, Hemophilus influenzae and Moraxella catarrhalis are also clinically relevant contributors to asthma exacerbation [14]. It is thought that these pathogenic microbes prevent the control of asthma exacerbation. This suggests that respiratory infection is a major factor of asthma exacerbation requiring hospitalization. On the other hand, the duration of hospitalization for asthma exacerbation with respiratory infection was not significantly different from that without respiratory infection in the elderly. This suggests that respiratory infection is not a major factor which makes the duration of hospitalization longer for elderly asthma exacerbation. That might be related to difficulty of control asthma in elderly patients. Although vaccination for influenza virus shows a protective effect against asthma exacerbation in children [14] and young adults [15], that is limited for elderly patients with asthma [15]. Thus, the immune system in elderly patients is different from that in younger ones, and this different immune system, apart from infection, might affect the recovery from asthma exacerbation. In summary, being elderly (65 years or over) is regarded as a factor that extends the duration of hospitalization for asthma exacerbation. Respiratory infection is supposed to be a major factor which determines the length of hospital stay in bronchial asthma exacerbation in patients under 65 years [16]. Oppositely, respiratory infection is not supposed to be a factor which determines the length of hospital stay in bronchial asthma exacerbation in elderly patients. The sample size is not large but it is considered to be the effective as a pilot investigation.

\section{References}

1. likura M, Hojo M, Koketsu R, Watanabe S, Sato A, et al. (2015) The importance of bacterial and viral infections associated with adult asthma exacerbations in clinical practice. PLoS One 10 (4): e0123584.

2. Soto-Campos JG, Plaza V, Soriano JB, Cabrera-López C, Almonacid-Sánchez C, et al. (2013) Causes of death in asthma, COPD and non-respiratory hospitalized patients: a multicentric study. BMC Pulm Med 13: 73.

3. Nakazawa T, Kawakami Y, Sudo M, Kobayashi S, Suetsugu S, et al. (2000) Asthma death among adults in Japan 1995-1997. Analysis of 295 cases reported questionnaires sent to hospitals with more than 100 beds. Asthma Death Investigation Committee. Arerugi 49: 505-511.

4. Gonzalez-Barcala FJ, Aboal J, Carreira JM, Rodriguez-Alvarez MX, Puga A, et al. (2012) Trends of asthma mortality in Galicia from 1993 to 2007. J Asthma 49:1016-1020.

5. Bartolomei-Díaz JA, Amill-Rosario A, Claudio L, Hernández W (2011) Asthma mortality in Puerto Rico: 1980-2007. J Asthma 48:202-209.

6. Schultze-Werninghaus G (2010) Asthma mortality in Germany - a critical evaluation. Pneumologie 64:392.

7. The Global Initiative for Asthma (GINA). Global Strategy for Asthma Management and Prevention 2006. 2006 Medical Communications Resources, Inc., 2006.

8. http://www.ginasthma.org/local/uploads/files/GINA_Report_2010_1.pdf

9. Health Welfare trend investigation in 2003 The Japanese ministry of Health, labor and Welfare.

10. Wang L, Wang K, Gao X, Paul TK, Cai J, et al. (2015) Sex difference in the association between obesity and asthma in U.S. adults: Findings from a national study. Respir Med.

11. Kurai D, Saraya T, Ishii H, Takizawa H (2013) Virus-induced exacerbations in asthma and COPD. Front Microbiol 4: 293.

12. McCoy L, Redelings M, Sorvillo F, Simon P (2005) A multiple cause-of-death analysis of asthma mortality in the United States, 1990-2001. J Asthma 42: 757-763.

13. Yamaya M (2012) Virus infection-induced bronchial asthma exacerbation. Pulm Med 2012:834826.

14. Kraft M (2000) The role of bacterial infections in asthma. Clin Chest Med 21: 301-313.

15. Yokouchi Y, Katsumori H, Shirakawa S, Fujiwara M, Kashima K, et al. (2014) Protective effects of influenza A (H1N1) pandemic 2009 vaccination against the onset of influenza-like illness and asthma exacerbation in Japanese children. J Asthma 51: 825-831.

16. Koshio N, Hasegawa T, Suzuki K, Tanabe Y, Koya T, et al. (2009) Niigata Asthma Treatment Study Group. Analysis of the influenza A (H1N1) 2009 pandemic infection in Japanese asthmatic patients: using a questionnairebased survey. Allergol 63: 67-74. 